\title{
Factors affecting baseline nociceptive sensitivity
}

\author{
LESLIE M. SCHUH \\ Wayne State University, Detroit, Michigan \\ and \\ J. BRUCE OVERMIER \\ University of Minnesota, Minneapolis, Minnesota
}

\begin{abstract}
The present study examined factors with the potential to affect sensitivity of the tail flick measure of thermal nociception in rats. The length of the habituation period before testing began, the apparatus ramp speed, and the light:dark cycle were manipulated in a within-subjects design to determine which factors minimize the variability between baseline trials. Factors had little effect on mean baseline latencies, but standard deviations were affected. Lower variability occurred after 0 - and 15-min habituation periods than after 60-min periods, after a constant light cycle than after a light:dark cycle, and after a higher temperature thermal apparatus than after a lower temperature. Although statistically significant, these effects were modest in size. These results may be of some use to those comparing studies that used very different parameters and to those designing studies and trying to optimize conditions.
\end{abstract}

The researcher who seeks to design a study that maximizes sensitivity to find existing treatment effects may use several major tactics. The two most common procedures for increasing power are to increase sample size and to use a research design that provides a more precise estimate of treatment effects and smaller error effects. To accomplish the latter, it is necessary to control response variability within and across sessions.

The tail flick test, first described by D'Amour and Smith (1941), is one of the most extensively used measures of nociceptive sensitivity (see, e.g., Calcagnetti \& Holtzman, 1992; Hole \& Tjolsen, 1993; Meagher, Chen, Salinas, \& Grau, 1993; Robertson \& Bodnar, 1993; Watkins, Wiertelak, Grisel, Silbert, \& Maier, 1992). Although the tail flick test is widely used, laboratories differ in their methodology, which results in substantial variability in baseline latencies. For example, Calcagnetti and Holtzman reported mean baseline latencies of $2 \mathrm{sec}$, whereas Meagher et al. reported latencies of 4.5 to $5 \mathrm{sec}$. For the researcher wishing to design protocols examining nociception as an endpoint, it may be difficult to identify the optimal set of parameters to uncover existing effects.

The present study was, therefore, designed to explore parameters that might alter baseline tail flick sensitivity and response variability across trials. If a combination of factors could be found in which subjects had less variable

The authors would like to acknowledge the helpful comments of Kory J. Schuh and Lisa M. Savage. Support for this research was provided by a National Science Foundation graduate fellowship to L.M.S. These data form part of L.M.S.'s doctoral dissertation submitted to the University of Minnesota in partial fulfillment of the requirements for a PhD degree. Correspondence should be sent to L. M. Schuh, Clinical Research Division on Substance Abuse, Department of Psychiatry, Wayne State University, 2761 East Jefferson Ave., Detroit, MI 48207 (e-mail: lschuh@med.wayne.edu). latencies over trials, this would decrease error variance, and, consequently, increase the sensitivity of the procedure to differences in latency due to experimental treatments of interest to psychologists studying learning, behavior, or pharmacology. Factors included in the present experiments were light:dark cycle (constant light or light:dark), tube restraint period before the trials began ("habituation"), and tail flick apparatus thermal test temperature. ${ }^{1}$ Each subject received exposure to all combinations of factors in a within-subjects design. This design maximizes the probability of finding existing effects because variance due to subjects is reduced. Two experiments were conducted.

\section{GENERAL METHOD}

\section{Subjects}

Six male Holtzman Sprague-Dawley rats, weighing $400-432 \mathrm{~g}$, were subjects in Experiment 1. Before this experiment, they had learned to leverpress for a water reinforcer. They were initially housed under $24 \mathrm{~h}$ of light. The animals had been under the constant light cycle for 3 months before testing began. At the beginning of the third phase of the experiment, a 14:10-h light:dark cycle was instituted with lights on at $0600 \mathrm{~h}$. Subjects remained under the light:dark cycle for 1 week before the third period of testing. Food and water were freely available. All testing was conducted between 0900 and $1230 \mathrm{~h}$, in the first half of the light period.

Ten rats, weighing 551-671 g, were subjects in Experiment 2. They, too, had formerly been trained to leverpress for water. Five animals were housed in the 24-h constant light cycle for 2 weeks before Phase 1 of the experiment, and 5 were housed in the 14:10-h light:dark cycle. Following Phase 1 testing, animals were rehoused and switched to the opposite lighting condition for 2 weeks before Phase 2 testing.

\section{Apparatus}

Two opaque Plexiglas tubes were used to restrain the animals lightly during testing. The tubes were $22 \mathrm{~cm}$ in length and had an internal diameter of $6.8 \mathrm{~cm}$. They were raised $6.7 \mathrm{~cm}$ off the ground 
and contained 22 ventilation holes $(0.8 \mathrm{~cm}$ in diameter). The fronts of the tubes were sealed by a sheet of opaque Plexiglas. The back was closed by a sliding Plexiglas gate with a slit $2.8 \mathrm{~cm}$ wide and $1.3 \mathrm{~cm}$ from the bottom of the tube through which the subject's tail protruded.

Analgesic testing was conducted using two identical radiant heat tail flick devices. A 375-W movie bulb (Sylvania, Type EBR) was positioned above the tail. A condenser lens below the bulb focused the light onto the approximate middle of the subject's tail. The same site was used from trial to trial to prevent this from becoming a source of variability in latency (Ness, Jones, \& Gebhart, 1987). The rat's tail rested horizontally on an aluminum block with a v-shaped groove $7.2 \mathrm{~cm}$ long, $1 \mathrm{~cm}$ wide, and $0.5 \mathrm{~cm}$ deep cut into it. A photocell below the groove automatically terminated a trial when the subject flicked its tail out of the groove at least $0.5 \mathrm{~cm}$. Trial length was automatically timed to the nearest $0.01 \mathrm{sec}$. At the beginning of each day of testing, the tail flick apparatus was calibrated at two temperatures by adjusting the heights of the bulb and lens of the apparatus. The high temperature produced a $26^{\circ} \mathrm{C}$ temperature increase in $15 \mathrm{sec}$, as measured by our glass mercury thermometer, and the low temperature produced a $20.5^{\circ} \mathrm{C}$ temperature increase in $15 \mathrm{sec}$. We will refer to them below as the "hot" and "cool" apparatus temperatures, respectively. A 12-sec tail flick cutoff was used in all phases of both experiments to prevent tissue damage.

\section{EXPERIMENT 1}

\section{Method}

This experiment consisted of three phases to examine (1) habituation period before tail flick testing, (2) light:dark cycle, and (3) tail flick apparatus temperature. All sessions consisted of three baseline latency trials at 2-min intervals. Before sessions began, subjects received 2 days of preexposure to the restraining tubes. Phase 1 lasted 8 days and was designed to look at the stability of latencies over days. Subjects received four daily sessions with either 15 - or $60-\mathrm{min}$ habituation periods before baseline tests and 4 days with the alternate habituation period before baseline tests. The thermal apparatus was set to the hot apparatus temperature.

In Phase 2, subjects received tail flick testing after both 0 - and 15-min habituation periods within a single session on 2 successive days. On the lst day, the thermal apparatus was set to the cool apparatus temperature, and on the 2 nd day, it was set to the hot apparatus temperature.

Before Phase 3 testing, subjects were shifted to the 14:10-h light:dark cycle for 1 week. On 2 successive days of testing, subjects received the same 0 - and 15 -min habituation periods before testing on the hot apparatus temperature (1st day) or cool apparatus temperature (2nd day).

Room temperature was $25.0^{\circ} \pm 1.2^{\circ} \mathrm{C}$ during Experiment 1.

\section{Results and Discussion}

Both mean tail flick latencies and standard deviations were analyzed for this experiment because it was not only the actual latency that was a concern, but also the variability of that latency. In Phase 1, animals received 4 days of baseline trials after a 60 -min habituation period and 4 days after a $15-\mathrm{min}$ habituation period. There were no significant differences in mean latency for habituation period $[F(1,5)=.0005]$, days $[F(3,15)=0.62]$, or their interaction $[F(3,15)=0.05]$. In the standard deviation analysis, however, habituation period did have an effect $[F(1,5)=$ $5.71, p<.01]$. Standard deviations were lower after the 15-min habituation period than after the 60 -min period. This finding raised the question of whether variability would be still smaller with no habituation period before trials; Phases 2 and 3 examined this question. Neither days nor the interaction of habituation period $X$ days had significant effects in the standard deviation analysis of Phase 1 $[F(3,15)=1.14$ for days, and $F(3,15)=1.87$ for the interaction].

Phases 2 and 3 of the experiment, conducted under a 24-h constant light cycle and a 14:10-h light:dark cycle, respectively, were combined to examine the effect of cycle on mean latency and standard deviation, in addition to habituation period and tail flick apparatus temperature. To increase the sensitivity of the analysis, preliminary tests were made of the interaction terms involving subjects, and, if they proved nonsignificant, they were removed from the model and pooled to increase the degrees of freedom $(d f)$ for the error term (Kirk, 1982; Winer, 1962). These preliminary tests were conducted at the $p=$ .25 level to minimize the chance of a Type II error (rejecting a component that actually exists in the population). Table 1 shows the expected mean square components contained in each source of variation. When an error mean square containing all the expected mean square components to test an effect was not available, it was sometimes necessary to create quasi- $F$ ratios that did contain all components, using Cochran's (1951) method.

For mean latency, shown in Figure 1, preliminary tests on the three-way subject interactions indicated that only the subjects $\times$ habituation period $\times$ temperature interaction could by pooled into the four-way subjects $x$ habituation period $\times$ temperature $\times$ cycle interaction $[F(5,5)=$ $0.69]$. The pooled mean square error term gave $10 d f$ for testing effects. Table 2 reports the $F$ tests performed and their results. No main effects or interactions of the mean latency data were significant.

Figure 1 also presents the standard deviation data. Preliminary tests indicated that all three-way interaction terms with subjects had significant effects [for subjects $\times$ temperature $X$ cycle, $F(5,5)=18.86, p<.01$; for subjects $\times$ habituation period $\times$ cycle, $F(5,5)=12.50, p<$ .01 ; and for subjects $\times$ habituation period $\times$ temperature, $F(5,5)=7.73, p<.05]$. These and the other tests of sources of variation are presented in Table 3 . There were

Table 1

Expected Mean Square Components

\begin{tabular}{|c|c|c|c|c|c|c|c|c|c|}
\hline Source of Variation & & & Exp & ected & Mean S & quare & & & \\
\hline $\mathrm{H}$ & $\mathrm{E}$ & SHTC & HTC & $\mathrm{SHC}$ & SHT & $\mathrm{CH}$ & HT & SH & $\mathbf{H}$ \\
\hline $\mathrm{S}(\mathrm{H})$ & $\mathrm{E}$ & SHTC & SHC & SHT & SH & & & & \\
\hline $\mathrm{T}$ & $\mathrm{E}$ & SHTC & HTC & STC & SHT & CT & HT & ST & $\mathbf{T}$ \\
\hline$S(T)$ & $\mathrm{E}$ & SHTC & STC & SHT & ST & & & & \\
\hline $\mathrm{H} \times \mathrm{T}$ & $\mathrm{E}$ & SHTC & HTC & SHT & HT & & & & \\
\hline C & $\mathrm{E}$ & SHTC & HTC & STC & SHC & CT & $\mathrm{CH}$ & $\mathrm{SC}$ & $\mathrm{C}$ \\
\hline$S(C)$ & $\mathrm{E}$ & SHTC & STC & SHC & $\mathrm{SC}$ & & & & \\
\hline $\mathrm{C} \times \mathrm{H}$ & $\mathrm{E}$ & SHTC & HTC & SHC & $\mathrm{CH}$ & & & & \\
\hline $\mathrm{C} \times \mathrm{T}$ & $\mathrm{E}$ & SHTC & HTC & STC & CT & & & & \\
\hline $\mathrm{H} \times \mathrm{T} \times \mathrm{C}$ & $\mathrm{E}$ & SHTC & HTC & & & & & & \\
\hline $\mathrm{S} \times \mathrm{H} \times \mathrm{T}$ & $\mathbf{E}$ & SHTC & SHT & & & & & & \\
\hline $\mathrm{S} \times \mathrm{H} \times \mathrm{C}$ & E & SHTC & SHC & & & & & & \\
\hline $\mathrm{S} \times \mathrm{T} \times \mathrm{C}$ & E & SHTC & STC & & & & & & \\
\hline $\mathrm{S} \times \mathrm{H} \times \mathrm{T} \times \mathrm{C}$ & $\mathrm{E}$ & SHTC & & & & & & & \\
\hline
\end{tabular}

Note- $\mathrm{H}$, habituation period; $\mathrm{T}$, tail flick temperature; $\mathrm{C}$, light:dark cycle; S, subjects; E, error. 

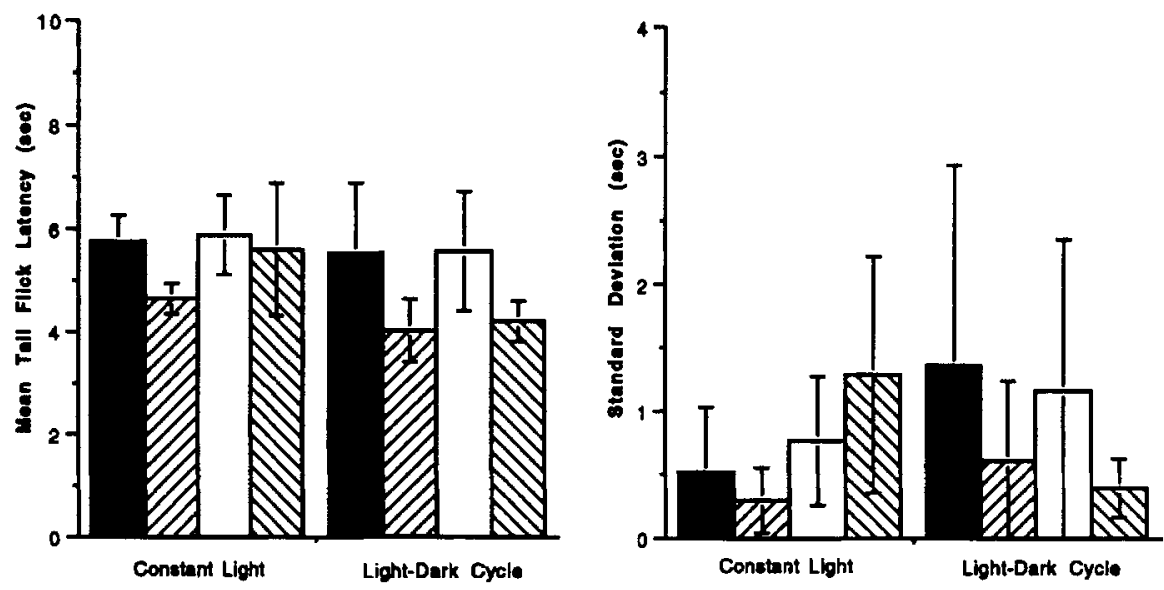

Figure 1. Means and standard deviations of nociceptive latency for subjects in Experiment 1 , Phases 2 and $3(n=6)$. Error bars are standard deviations.

no significant effects of habituation period, apparatus temperature, cycle, or any two-way interactions between these factors. Only the three-way interaction of habituation period $\times$ temperature $\times$ cycle reached significance $[F(1,5)=9.77, p<.05]$. Follow-up tests revealed that certain combinations of factors (e.g., 0 -min habituation period, hot apparatus, and constant light) were significantly different from others (e.g., 0 -min habituation, cool apparatus, 14:10-h light:dark cycle). However, the size of the interaction was small, accounting for a mere $1.06 \%$ of the variation of the standard deviations $\left(\omega^{2}\right)$.

Taken together, the mean latency data from Experiment 1 reveal that habituation period, thermal apparatus temperature, and light:dark cycle are not major influences on mean baseline tail flick latency. The standard deviation data are more complex. Although Phase 1 revealed that a 60-min habituation period produced greater variability than did a 15-min habituation period, no influence was found in Phases 2 and 3 when 15- and 0-min habituation periods were compared. Some combinations of factors led to lower standard deviations than did others, but no simple hypotheses were capable of accounting for the data, and the effect size of this three-way interaction was very small.

Table 2

Analysis of Mean Latencies in Experiment 1

\begin{tabular}{|c|c|c|c|c|}
\hline $\begin{array}{l}\text { Source of } \\
\text { Variation }\end{array}$ & $d f$ & $F$ test & $F$ ratio & $p$ \\
\hline $\mathrm{H}$ & 1,5 & $\mathrm{H} / \mathrm{SH}$ & 2.05 & n.s. \\
\hline $\mathrm{S}(\mathrm{H})$ & 5,5 & $\mathrm{SH} / \mathrm{SHC}$ & 0.68 & n.s. \\
\hline $\mathrm{T}$ & 1,3 & $(\mathrm{~T}+$ Residual $) /(\mathrm{ST}+\mathrm{CT})$ & 4.89 & n.s. \\
\hline$S(T)$ & 5,10 & ST/STC & 0.68 & n.s. \\
\hline $\mathrm{H} \times \mathrm{T}$ & 1,10 & HT/Residual & 3.2 & n.s. \\
\hline $\mathrm{C}$ & 1,6 & $(\mathrm{C}+$ Residual $) /(\mathrm{SC}+\mathrm{CT})$ & 0.78 & n.s. \\
\hline$S(C)$ & 5,9 & $(\mathrm{SC}+\mathrm{Residual}) /(\mathrm{STC}+\mathrm{SHC})$ & 1.97 & $p<.25$ \\
\hline $\mathrm{C} \times \mathrm{H}$ & 1,5 & $\mathrm{CH} / \mathrm{SHC}$ & 1.5 & n.s. \\
\hline $\mathrm{C} \times \mathrm{T}$ & 1,5 & $\mathrm{CT} / \mathrm{STC}$ & 3.36 & n.s. \\
\hline $\mathrm{H} \times \mathrm{T} \times \mathrm{C}$ & 1,10 & HTC/Residual & 1.39 & n.s. \\
\hline $\mathrm{S} \times \mathrm{H} \times \mathrm{C}$ & 5,5 & SHC/SHTC & 3.32 & $p<.25$ \\
\hline $\mathrm{S} \times \mathrm{T} \times \mathrm{C}$ & 5,5 & STC/SHTC & 6.2 & $p<.05$ \\
\hline
\end{tabular}

Note- $\mathrm{H}$, habituation period; $\mathrm{T}$, tail flick temperature; $\mathrm{C}$, light:dark cycle; S, subjects.
Because subjects spent just 1 week in the light:dark cycle, it may be that they were not yet fully adapted to the cycle. Because the tail flick test is a measure of thermal responsiveness, findings on circadian rhythmicity in body temperature may be relevant to this issue. In the rat, body temperature fluctuations are related to the light:dark cycle, with a stable body temperature occurring during the light phase, when the animal is typically at rest, and an increase during the middle of the dark portion of the cycle, when the animal is typically most active (Gordon, 1990). Fioretti, Riccardi, Menconi, and Martini (1974) reported that when the cycle was changed, 9-13 days were required for the body temperature to adapt to the new schedule. On the basis of these data, it might be argued that subjects in Experiment 1 were not fully adapted to the new cycle, and that their tail flick latencies were not stable. To address this concern, Experiment 2 allowed at least 2 weeks of exposure to each cycle before testing began. Half of the subjects received the constant light:cycle first, and half received the light:dark cycle first.

\section{EXPERIMENT 2}

\section{Method}

All subjects received two exposures to the restraining tubes before the first tail flick session of Phase 1 . Subjects were tested with the cool temperature tail flick apparatus on the $1 \mathrm{st}$ day of the first block of trials and the hot temperature apparatus on the 2nd day. The first 0 -min habituation period trial began immediately upon placement in the tubes. Animals received three tail flick trials at 2 -min intervals. They received a second set of three trials after $15-$ min habituation in the tubes.

In Phase 2 of the study, animals were rehoused in the alternate light:dark cycle for 14 days before testing. On the 1st day of testing, they received the hot thermal apparatus temperature and on the 2nd day, they received the cool temperature; otherwise the procedure was the same as that in Phase 1.

Room temperature was $25.3^{\circ} \pm .3^{\circ} \mathrm{C}$ in Experiment 2.

\section{Results and Discussion}

The data analysis for Experiment 2 was similar to that for Phases 2 and 3 of Experiment 1, except an additional 
Table 3

Analysis of Standard Deviations of Latency in Experiment 1

\begin{tabular}{|c|c|c|c|c|}
\hline $\begin{array}{l}\text { Source of } \\
\text { Variation }\end{array}$ & $d f$ & $F$ test & $F$ ratio & $p$ \\
\hline $\mathbf{H}$ & 1,5 & $\mathrm{H} / \mathrm{SH}$ & 2.13 & n.s. \\
\hline $\mathrm{S}(\mathrm{H})$ & 7,9 & $(\mathrm{SH}+\mathrm{Residual}) /(\mathrm{SHT}+\mathrm{SHC})$ & 0.32 & n.s. \\
\hline $\mathrm{T}$ & 1,5 & $\mathrm{~T} / \mathrm{S}(\mathrm{T})$ & 1.1 & n.s. \\
\hline$S(T)$ & 5,9 & $(\mathrm{ST}+$ Residual $) /(\mathrm{STC}+\mathrm{SHT})$ & 0.89 & n.s. \\
\hline $\mathrm{H} \times \mathrm{T}$ & 1,3 & $(\mathrm{HT}+\mathrm{Residual}) /(\mathrm{SHT}+\mathrm{HTC})$ & 0.56 & n.s. \\
\hline $\mathrm{C}$ & 1,1 & $\mathrm{C} / \mathrm{SC}$ & 0.27 & n.s. \\
\hline$S(C)$ & 5,10 & $(\mathrm{SC}+\mathrm{Residual}) /(\mathrm{SHC}+\mathrm{STC})$ & 0.91 & n.s. \\
\hline $\mathrm{C} \times \mathrm{H}$ & 1,1 & $\mathrm{CH} / \mathrm{HTC}$ & 4.79 & n.s. \\
\hline $\mathrm{C} \times \mathrm{T}$ & 1,1 & $\mathrm{CT} / \mathrm{HTC}$ & 5.77 & n.s. \\
\hline $\mathrm{H} \times \mathrm{T} \times \mathrm{C}$ & 1,5 & HTC/Residual & 9.77 & $p<.05$ \\
\hline $\mathbf{S} \times \mathbf{H} \times \mathbf{T}$ & 5,5 & SHT/SHTC & 7.73 & $p<.05$ \\
\hline $\mathbf{S} \times \mathbf{H} \times \mathbf{C}$ & 5,5 & SHC/SHTC & 12.5 & $p<.01$ \\
\hline $\mathrm{S} \times \mathrm{T} \times \mathrm{C}$ & 5,5 & STC/SHTC & 18.86 & $p<.01$ \\
\hline
\end{tabular}

Note- $-\mathrm{H}$, habituation period; $\mathrm{T}$, tail flick temperature; $\mathrm{C}$, light:dark cycle; $\mathrm{S}$, subjects.

blocking factor existed: which cycle the animals received first, constant light or light:dark. This blocking factor was tested for significance in the mean latency and standard deviation analyses and found to have no effect on latencies $[F(1,8)=3.03$ for blocks in the mean latency data and $F(1,8)=0.08$ for blocks in the standard deviation data]. Therefore, the blocking factor was removed from both models, and analyses were conducted as in Phases 2 and 3 of Experiment 1.

Tables 4 and 5 present the $F$ tests and ratios for the mean latencies and standard deviations, respectively.

Figure 2 shows the mean latency for all conditions. In the mean latency analysis, preliminary tests of the interactions with subjects indicated that the subjects $\times$ habituation period $\times$ temperature factor was not significant $[F(9,9)=1.27, p>.25]$ and could be removed from the model and pooled with the error mean square. There were significant effects at the $p=.25$ level for both the subjects $\times$ habituation period $\times$ cycle interaction and the subjects $\times$ temperature $\times$ cycle interaction, so these could not be pooled. The only other significant source of variation was the three-way interaction of habituation period $\times$ temperature $\times$ cycle. Some combinations of factors were significantly different from others, but the pattern was complex. Calculation of $\omega^{2}$ indicated that the effect size of this interaction was small, accounting for only $1.76 \%$ of the variance of mean latency.

The data on standard deviations are also plotted in Figure 2. Preliminary tests for interactions with subjects indicated that the subjects $\times$ habituation period $\times$ temperature interaction $[F(9,9)=0.545]$ and the subjects $\times$ temperature $\times$ cycle interaction $[F(9,9)=1.02]$ could be deleted from the model and pooled with error to give $27 d f$ for tests of some factors. The subjects $\times$ habituation period $\times$ cycle interaction, however, was significant at the $p=.25$ level. Table 5, containing the tests of this three-way interaction and the other sources of variation within the model, shows that both temperature and cycle had significant effects $[F(1,9)=7.59, p<.05$ for temperature and $F(1,9)=5.71, p<.05$ for cycle]. When sub- jects were tested under the hot thermal apparatus temperature, they generally had less variable latencies than when they were tested under the cool temperature apparatus. The cycle factor had a significant effect because animals generally had less variable baselines under the 24h light cycle than under the light:dark cycle. Finally, the habituation period $\times$ temperature interaction reached significance $[F(1,27)=4.75, p<.05]$ because in the 15 min habituation period, baselines were less variable when tested with the hot temperature apparatus than with the cool temperature apparatus, but no difference in standard deviation based on apparatus temperature occurred in the 0 -min habituation period. Calculation of $\omega^{2}$ for these data indicated that apparatus temperature accounted for $5.41 \%$, cycle accounted for $4.63 \%$, and the interaction of habituation and apparatus temperature accounted for $2.07 \%$ of the variance in the standard deviation scores.

The results of this second replication indicate that the mean baseline latencies of subjects were not affected by habituation period, thermal apparatus temperature, or light:dark cycle factors alone. Some combinations of the three factors produced longer baselines than did other combinations, but it is difficult to explain the meaning of the interaction, and it accounts for a small amount of the variance in latency.

Table 4

Analysis of Mean Latencies in Experiment 2

\begin{tabular}{|c|c|c|c|c|}
\hline $\begin{array}{l}\text { Source of } \\
\text { Variation }\end{array}$ & $d f$ & $F$ test & $F$ ratio & $p$ \\
\hline $\mathrm{H}$ & 1,9 & $\mathrm{H} / \mathrm{SH}$ & 0.51 & n.s. \\
\hline $\mathrm{S}(\mathrm{H})$ & 9,9 & $\mathrm{SH} / \mathrm{SHC}$ & 1.29 & n.s. \\
\hline $\mathrm{T}$ & 1,9 & $\mathrm{~T} / \mathrm{ST}$ & 0.006 & n.s. \\
\hline $\mathrm{S}(\mathrm{T})$ & 9,9 & ST/STC & 2.44 & n.s. \\
\hline $\mathrm{H} \times \mathrm{T}$ & 1,1 & $\mathrm{HT} / \mathrm{HTC}$ & 0.27 & n.s. \\
\hline $\mathrm{C}$ & 1,9 & $\mathrm{C} / \mathrm{SC}$ & 0.91 & n.s. \\
\hline$S(C)$ & 11,16 & $(\mathrm{SC}+$ Residual $) /(\mathrm{STC}+\mathrm{SHC})$ & 1.66 & n.s. \\
\hline $\mathrm{C} \times \mathrm{H}$ & 2,1 & $(\mathrm{CH}+\mathrm{Residual}) /(\mathrm{SHC}+\mathrm{HTC})$ & 0.415 & n.s. \\
\hline $\mathrm{C} \times \mathrm{T}$ & 2,2 & $(\mathrm{CT}+$ Residual $) /(\mathrm{STC}+\mathrm{HTC})$ & 0.29 & n.s. \\
\hline $\mathrm{H} \times \mathrm{T} \times \mathrm{C}$ & 1,18 & HTC/Residual & 10 & $p<.01$ \\
\hline $\mathrm{S} \times \mathrm{H} \times \mathrm{C}$ & 9,9 & SHC/SHTC & 1.97 & $p<.25$ \\
\hline $\mathrm{S} \times \mathrm{T} \times \mathrm{C}$ & 9,9 & STC/SHTC & 4.5 & $p<.05$ \\
\hline
\end{tabular}

Note- $-\mathrm{H}$, habituation period; $\mathrm{T}$, tail flick temperature; $\mathrm{C}$, light:dark cycle; S, subjects.

Table 5 Analysis of Standard Deviations of Latency in Experiment 2

\begin{tabular}{lllcc}
\hline $\begin{array}{l}\text { Source of } \\
\text { Variation }\end{array}$ & $d f$ & \multicolumn{1}{c}{$F$ test } & $F$ ratio & $p$ \\
\hline $\mathrm{H}$ & 1,9 & H/SH & 0 & n.s. \\
$\mathrm{S}(\mathrm{H})$ & 9,9 & SH/SHC & 0.43 & n.s. \\
$\mathrm{T}$ & 1,9 & T/ST & 7.59 & $p<.05$ \\
$\mathrm{~S}(\mathrm{~T})$ & 9,27 & ST/Residual & 1.46 & n.s. \\
$\mathrm{H} \times \mathrm{T}$ & 1,27 & HT/Residual & 4.75 & $p<.05$ \\
$\mathrm{C}$ & 1,9 & C/SC & 5.71 & $p<.05$ \\
$\mathrm{~S}(\mathrm{C})$ & 9,9 & SC/SHC & 0.84 & n.s. \\
$\mathrm{C} \times \mathrm{H}$ & 1,9 & CH/SHC & 0.43 & n.s. \\
$\mathrm{C} \times \mathrm{T}$ & 1,27 & CT/Residual & 0.09 & n.s. \\
$\mathrm{H} \times \mathrm{T} \times \mathrm{C}$ & 1,27 & HTC/Residual & 0.85 & n.s. \\
$\mathrm{S} \times \mathrm{H} \times \mathrm{C}$ & 9,9 & SHC/SHTC & 2.23 & $p<.25$ \\
\hline
\end{tabular}

Note- $\mathrm{H}$, habituation period; $\mathrm{T}$, tail flick temperature; $\mathrm{C}$, light:dark cycle; S, subjects. 

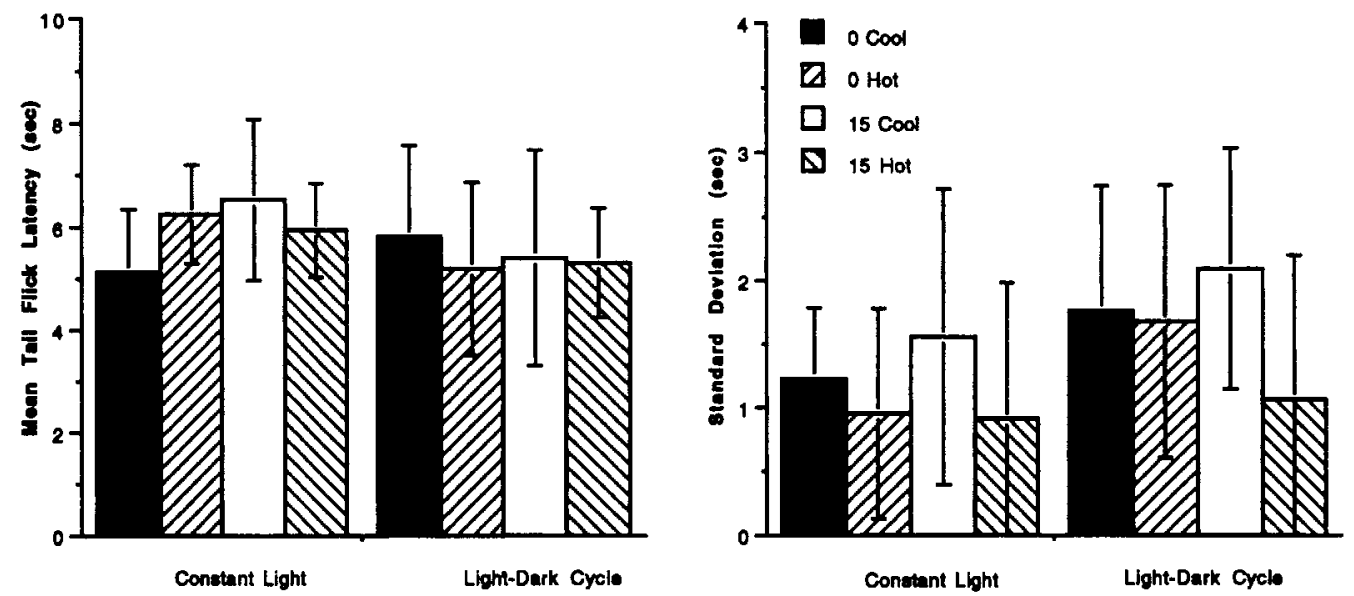

Figure 2. Means and standard deviations of nociceptive latency for subjects in Experiment $2(n=10)$. Error bars are standard deviations.

In contrast, the baseline variability was more affected by these variables. Subjects had less variable baselines when the hot apparatus temperature was used and when they had been housed on the 24-h light cycle. Although habituation period did not have an effect of its own on baseline variability, it did enter into an interaction with thermal apparatus temperature. Subjects tested after a 15-min habituation period had less variable baseline latencies with the hot apparatus temperature than with the cool apparatus temperature. Apparatus temperature did not affect baseline variability of animals after a 0 -min habituation period. These factors have a small but perhaps important effect on baseline variability.

This second replication was a stronger experiment than the first in several respects. Subjects were counterbalanced on which cycle they received first, and they spent more time in each cycle condition than did those tested in the first replication. Because of these procedural differences, we can lend greater credence to the results of the second replication in guiding future work. Using the hot apparatus temperature and the constant light cycle may produce a modest decrease in baseline variability.

\section{GENERAL DISCUSSION}

Factors affecting baseline nociceptive latency were expected to affect sensitivity to shock-induced hypoalgesia also, and the present experiments were designed to improve procedural sensitivity by examining such factors. O'Callaghan and Holtzman (1975) reported that manipulating temperatures of the hot plate test of thermal nociception affected its sensitivity to drug effects. Lower temperatures produced longer latencies and were more sensitive to the analgesic effect of narcotics. The tail flick test of thermal nociception used here was expected to be affected by apparatus temperature also. Indeed, recent studies have indicated that apparatus temperature determines the neurological components of the tail flick response. Although the tail flick response is a spinal reflex
(Jensen \& Yaksh, 1986a; Schmauss \& Yaksh, 1984), it also contains a supraspinal component when apparatus temperature is reduced to produce a longer tail flick latency, as in the present study ( $4-6$ vs. $2-3 \mathrm{sec}$ ). Jensen and Yaksh (1986b) reported that spinal transsection abolishes the tail flick response induced by a lower temperature apparatus, whereas the tail flick response induced by a higher temperature apparatus remained intact.

However, the results indicated that thermal apparatus temperature, habituation period, and light cycle had less effect on mean baseline latency than on variability between trials. Smaller standard deviations occurred for animals tested with (1) the warmer temperature thermal apparatus than with the cooler apparatus, (2) 0 - and 15-min habituation periods than with 60 -min periods, and (3) the constant light cycle than with the 14:10-h light:dark cycle. The finding that the warmer apparatus temperature was associated with smaller standard deviations is consistent with Jensen and Yaksh's (1986b) finding that there is less of a supraspinal component to the tail flick response when the apparatus temperature is raised. None of the factors examined in the present study was a major controller of variance. This finding may be of some use to those trying to make comparisons across experiments in which the factors studied are at different levels or to those planning experiments and trying to select conditions.

\section{REFERENCES}

Calcagnetti, D. J., \& Holtzman, S. G. (1992). Intake of sweet water attenuates restraint-stress-induced potentiation of morphine analgesia in rats. Brain Research Bulletin, 29, 859-864.

Cochran, W. G. (1951). Testing a linear relation among variances. Biometrics, 7, 17-32.

D'Amour, F. E., \& SMITH, D. L. (1941). A method for determining loss of pain sensation. Journal of Pharmacology \& Experimental Therapeutics, 72, 74-79.

Fioretti, M. C., Riccardi, C., Menconi, E., \& Martini, L. (1974). Control of the circadian rhythm of the body temperature in the rat. Life Sciences, 14, 2111-2119.

Gordon, C. J. (1990). Thermal biology of the laboratory rat. Physiology \& Behavior, 47, 963-991. 
Hole, K., \& Tuolsen, A. (1993). The tail flick and formalin tests in rodents: Changes in skin temperature as a confounding factor. Pain, $\mathbf{5 3}$ 247-254

JENSEN, T. S., \& YAKSH, T. L. (1986a). Comparison of antinociceptive action of morphine in the periaquaductal gray, medial and paramedial medulla in rat: I. Brain Research, 363, 99-113.

JENSEN, T. S., \& YAKSH, T. L. (1986b). Examination of spinal monoamine receptors through which brainstem opiate-sensitive systems act in the rat: II. Brain Research, 363, 114-127.

KirK, R. E. (1982). Experimental design (2nd ed.). Pacific Grove, CA: Brooks/Cole.

Meagher, M. W., Chen, P.-S., Salinas, J. A., \& Grau, J. W. (1993). Activation of the opioid and nonopioid hypoalgesic systems at the level of the brainstem and spinal cord: Does a coulemetric relation predict the emergence or form of environmentally induced hypoalgesia? Behavioral Neuroscience, 107, 493-505.

Ness, T. J., Jones, S. L., \& GebHart, G. F. (1987). Contribution of the site of heating to variability in the latency of the rat tail flick reflex. Brain Research, 426, 169-172.

O'Callaghan, J. P., \& Holtzman, S. G. (1975). Quantification of the analgesic activity of narcotic antagonists by a modified hot-plate procedure. Journal of Pharmacology \& Experimental Therapeutics, 192, 497-505.

RoBERTSON, J. A., \& BodNAR, R. J. (1993). Site-specific modulation of morphine and swim-induced antinociception following thyrotropinreleasing hormone in the rat periaquaductal gray. Pain, 55, 71-84.

Schmauss, C., \& YaKsh, T. L. (1984). In vivo studies on spinal opiate receptor systems mediating antinociception: II. Pharmacological profiles suggesting a differential association of mu, delta, and kappa receptors with visceral chemical and cutaneous thermal stimuli in the rat. Journal of Pharmacology \& Experimental Therapeutics, 228, 1-12.

Watkins, L. R., Wiertel.ak, E. P., Grisel, J. E., Silbert, L. H., \& MAIER, S. F. (1992). Parallel activation of multiple spinal opiate systems appears to mediate "non-opiate" stress-induced analgesias. Brain Research, 594, 99-108.

WINER, B. J. (1962). Statistical principles in experimental design. New York: McGraw-Hill.

\section{NOTE}

1. J. W. Grau (personal communication, March 1990) suggested that the apparatus ramp speed and habituation period may have important effects on latency. At the time this experiment was designed, a timer capable of regulating the lights in the animal colony room was installed, leading the experimenter to examine the effects of this factor as well. Since body temperature does fluctuate with light:dark cycles (Gordon, 1990 ) and has been correlated with latency to move the tail from a thermal stimulus (see Hole \& Tjolsen's 1993 review), this variable appeared potentially capable of influencing latency.

(Manuscript received March 1, 1995; revision accepted for publication August 7, 1996.) 